\title{
Ergonomic basket design to reduce cumulative trauma disorders in tea leaf plucking operation
}

\author{
Bhattacharyya, $\mathrm{N}^{1}$; Chakrabarti, $\mathrm{D}^{2}$ \\ ${ }^{1}$ Assam Agricultural University, Jorhat, Assam, India, \\ ${ }^{2}$ Department of Design, Indian Institute of Technology, Guwahati, Assam, India
}

\begin{abstract}
Work related musculoskeletal disorders are seen as an indicating parameter of occupational stress among the women workers engaged in tea leaf plucking operation. The hand plucking (no mechanized plucking is practiced in Assam) being a highly repetitive task requires forceful exertions to reach to the distant periphery of the tea bushes and mechanical compression (pressing against hard surfaces). Specifically it aggravates with awkward positions adopted. The current research addresses to minimize the risk factors associated with CTDs and to ascertain the role of ergonomic design development in improving the situation. Women workforce engaged in tea industry in Assam suffer from back, shoulder, arm and finger pains. Workers perform the activity for 440 minutes in the entire shift with one hour lunch break in between in the garden itself. An ergonomic investigation aiming at studying the strain index of plucking operation in tea industry was conducted. While performing the operation workers were found to assume unnatural posture which is static as well as highly dynamic with a load (tea leaf collecting basket up to weight of $30 \mathrm{~kg}$ when filled with plucked leaves) at back. With gradual increment of load and pain though the load is released intermittently the strain level found to remain at a high level. The total QEC scores found for plucking activity was 110 out of 138 . To improve the situation and to reduce the work related upper limb disorder (WRULD) an ergonomically designed basket was conceived and trial results showed improvements. The newly designed plucking basket fits the back curvature of the workers well, which keeps the basket in place unlike the existing round basket. The new basket is light in weight having more leaf capacity. Significant reduction in energy expenditure and MSDs suffered was observed while using improved basket over existing basket.
\end{abstract}

Keywords: tea leaf plucking operation; CTD; ergonomic design intervention

\section{Introduction}

In India joining of women in the workforce is increasing in numbers, especially in industry and service sector where repetitive work is required. Due to their low literacy level and lack of technical knowledge, mostly women workers are engaged in occupations with repetitive, monotonous and low-paid work. The sectors where women workers are the prime workforce include agriculture, agro based industry (tea, fruit processing, cottage industries, etc) and services; making up about 42 per cent of the estimated global working population along with their homemaking responsibilities. Often they handle two or more tasks simultaneously. They are therefore prone to suffer from work-related diseases, ${ }^{*}$ which are further complicated by social, psychological and physiological issues. The exposure of women workers to these issues may affect them in one or more of three ways: health, performance, and comfort. Studies have shown that roughly, 1 out of 300 female is suffering from some occupation related diseases. Musculoskeletal disorders are the major problems among many women workers in industries $[4,5,6]$.

\footnotetext{
${ }^{*}$ Corresponding author e-mail: nandita@iitg.ernet.in
} 
The causative factors of musculoskeletal disorders are poor ergonomic design of work place, work accessories, poor working posture, repetitive work, and static work, frequent bending and twisting, lifting and forceful movements and vibration. Individual factors like age, sex, anthropometric, dimensions, muscle strength and physical fitness, lack of task variation, insufficient rest break, psychological and social factors contribute to musculoskeletal disorders. The women workers often suffer from musculoskeletal disorders because neither the tasks nor the equipment they use, which are normally designed for men are adapted to their built and physiology.

In most industrial situations women workers usually perform manual tasks involving repetitive arm movements. The task may not involve heavy exertion, but fatigue, pain and repetitive strain injuries in arm, shoulder and neck region are prevalent. It is also agreed that working for prolonged periods while performing repetitive tasks can be very damaging to both productivity as well as worker's health [9]. This is because static muscle exertion inhibits blood flow and causes muscle fatigue. The buildup of fatigue can minimize the overall effectiveness of worker productivity as well as reduced output.

The ergonomics risks factors in an occupational set up while performing any activity can be tackled by developing safe, trust worthy design [2]. Hence, to increase efficiency in work performances, importance should be given on the working condition, design of the work accessories/machines and health of the workers as well as providing better facilities for them. Work accessories/machines should be designed according to ergonomic requirements. In practice, before design development studying the risk factors in occupational setting in organized way is the correct approach

The Tea Industry is one of the largest employers of women amongst organized industries in India. Women constitute nearly $51 \%$ of the total workforce in Assam. Many of the activities, especially the plucking activity (40 per cent of the total cost of production of tea leaves) performed by the workers in tea plantation demand a high degree of physical effort because of repetitiveness and assuming static awkward posture, leading to early fatigue and work related musculoskeletal problems. Ergonomic intervention in designing work accessories can reduce work related stress by assisting the plucking operation. Thus, this study was carried out -1 ) to assess the occupational loads on women workers engaged in tea-leaf plucking operation and 2) to identify specific design development of work tools and accessories.

\subsection{The subjects}

A total sample of 180 women workers actively involved (at least for 10 years) in performance of plucking of tea leaves in the age group of 35-50 years were selected by following purposive sampling procedure from Jorhat district, Assam, India.

\subsection{Ergonomic risks factors analyses}

Ergonomic risk factors prevailed among women workers (tea leaf pluckers) associate productivity and relevant health issues were quantified using two techniques: OCRA (Occupational Repetitive Assessment), and Quick Exposure Check (QEC)

\subsection{Occupational load}

Occupational load of tea leaf plucking operation was studied by measuring the following stress factors of the workers while performing the selected activity.

\subsubsection{Rating of Perceived Exertion (RPE):}

Subjective rating of feeling of tiredness was studied by using the Rating scale of Perceived Exertion (RPE), developed by Varghese et al (1994). The exertion perceived by the subject during and after the activity was recorded was categorized as very heavy, heavy, moderately heavy, light and very light based on the scores from 5,4,3,2 and 1 respectively.

\subsubsection{Physiological cost of work}

Heart rate is an indicator of cardiac stress due to physical workload. Heart rate was recorded after every five minutes during experiment using polar heart rate monitor. From the average values of heart rate, energy expenditure was calculated with the help of formulae given by Varghese et al (1994) as below:

$$
\left.\mathrm{EE}\left(\mathrm{Kj}^{-\mathrm{min}}\right)=0.159 \times \text { AHR (beats per min. }\right)-8.72
$$

\subsubsection{Occupational stress-WMSDs and MSDs}

NMQ (Nordic Musculoskeletal Questionnaire) and the body map were used to gather data on cumulative trauma disorders (MSDs).

\subsection{Statistical analysis}

The frequencies, percentage, mean and standard deviations were calculated to answer the various questions relevant to the objectives of the study.

\section{Methodology}




\section{Results and discussion}

3.1 Physical and demographic characteristics of the selected women workers engaged in tea plucking operation stature

Demographically, tea garden labour community of Assam represents around 20 per cent of the total population of the state accounting more than 45 lakhs tea garden labour population in the state and is one of the biggest contributors to the organised workforce as well as to the economy of Assam. About 17 per cent of workers in Assam are engaged in tea industry and around 50 per cent of the total tea plantation workforce in Assam is women. [11]

The mean age for the studied women tea pluckers was 35.44 years, ranging from 19 years to 55 years, having $46.61 \mathrm{~kg}$ body weight and years and lowest belonged to the age group of above 55 years. $159.76 \mathrm{~cm}$ height. The highest mean body weight of the respondents belonged to the age group of 16 to 25 years.

Table 1

Physical characteristics of the Respondents

\begin{tabular}{|l|l|l|}
\hline Parameters & Mean & + S.D. \\
\hline Age (Years) & 35.44 & 11.61 \\
\hline Weight $(\mathrm{Kg})$ & 46.61 & 4.30 \\
\hline Height $(\mathrm{cm})$ & 159.76 & 2.8 \\
\hline BMI & 17.76 & 2.01 \\
\hline
\end{tabular}

\subsection{Ergonomic risk factors}

A good understanding of ergonomics provides the basis for a sound analysis of the current situations [3]. In the present study efforts were made to identify the ergonomics risk factors in plucking operation. It was observed that in plucking of tea leaves, the workers performed the operation in standing posture with slight bending near neck and low back (Fig.1).

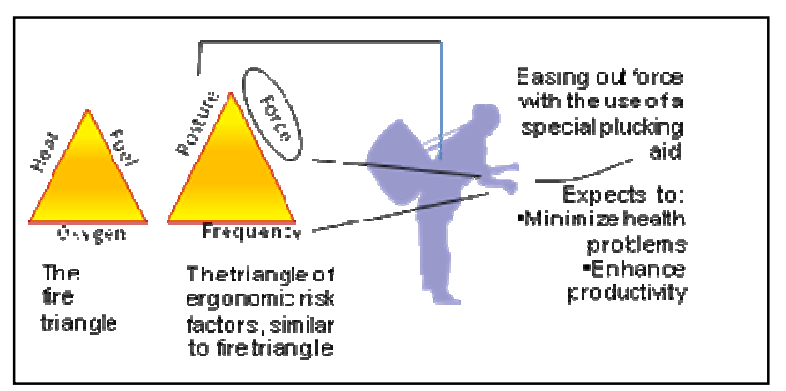

Figure1. Ergonomic risk factors

The arms were found outstretched to reach the leaves and finger moves repetitively. Moreover the workers had to carry plucking baskets on their back, hanging mostly from head (with a strap) to keep the plucked leaves. From the observed posture it can be concluded that ergonomic risk factors such as the awkward posture, pinch force with twisted movements used to pluck the leaves. The workers perform the activity in the entire shift with highly repetitive movement. According to Wiker et al (1990) that sustained work with awkward or biomechanically stressful postures increased the risk of tea leaf pluckers.

This indicates that the plucking operation and working conditions were conducive for developing musculoskeletal disorders e.g., awkward postures affect the shoulder and upper limbs in general and lead to WMSDs in the long run. With the ergonomic risk factors prevailing in tea leaf plucking operation, occupational stress was seen among the tea leaf pluckers. This indicates that the plucking operation and working conditions were conducive for developing MSDs.

\subsubsection{The OCRA Index}

The Occupational Repetitiveness Assessment (OCRA) method was used for analyzing workers' exposure to tasks featuring various upper limb risk factors. The Concise Exposure Index (OCRA) quantified the relationship between the daily number of actions actually performed by the upper limbs in repetitive tasks, and the corresponding number of recommended actions and also evaluated the main collective risk factors (frequency of action, awkward postures and movements of the upper limbs, excessive use of force, 'stereotypy' or lack of postural variation, inadequate recovery periods) based on their respective duration.

Table 2

Results of the analysis of OCRA Index and OCRA check list

\begin{tabular}{|l|c|c|l|l|l|l|}
\hline Task & \multicolumn{2}{|l|}{ OCRA index } & \multicolumn{2}{l|}{$\begin{array}{l}\text { OCRA } \\
\text { checklist } \\
\text { values }\end{array}$} & \multicolumn{2}{l|}{$\begin{array}{l}\text { Risk } \\
\text { Level/Risk } \\
\text { Area }\end{array}$} \\
\hline $\begin{array}{l}\text { Plucking } \\
\text { operation }\end{array}$ & $\begin{array}{l}\text { Right } \\
\text { Arm }\end{array}$ & $\begin{array}{l}\text { Left } \\
\text { Arm }\end{array}$ & $\begin{array}{l}\text { Right } \\
\text { Arm }\end{array}$ & $\begin{array}{l}\text { Left } \\
\text { Arm }\end{array}$ & $\begin{array}{l}\text { Right } \\
\text { Arm }\end{array}$ & $\begin{array}{l}\text { Left } \\
\text { Arm }\end{array}$ \\
\hline & 11.83 & 9.4 & 29.5 & 24.5 & High & High \\
\hline
\end{tabular}

For plucking operation the OCRA index score was found 11.83 for right arm and 9.4 for left arm, indicates high risk involvement. Actual Technical Action for the entire shift was found 40,813 (78 numbers of frequency ${ }^{-}$ ${ }^{\min }$ for 375 minutes duration) for right hand and 32,442 (62 numbers of frequency ${ }^{-\mathrm{min}}$ for 375 minutes duration) for left hand. In case of OCRA checklist values for right arm and left arm it was found 29.5 and 24.5 
respectively (table 2). The strain index both OCRA index and OCRA checklist values indicate high risk involvement in the plucking activity and immediate changes are required either in work method or in work tools or in work station.

\subsubsection{Quick Exposure Check (QEC)}

The analyses of plucking operation using QEC gives exposure scores to specific body parts including the back, shoulder/arm, wrist/hand, and neck. The total QEC score for plucking operation found was 110 out of 138. The maximum QEC scores (Fig.2) found was for neck i.e., 88.88 , because the workers perform the activity with the neck in bending posture with cocontraction in neck muscles along with a heavy basket (weighing up to $30 \mathrm{~kg}$ ) hung from the head to keep the plucked leaves. The QEC scores for back was also found high (88.23) because of when performing the activity, the back is flexed continuously. In case of shoulder and wrist/hand the QEC scores were more than 70 percent i.e., 75 percent and 73.33 percent respectively. Several studies reported that for tasks other than manual handling, static postural loading has been shown to be a risk factor for low back pain (LBP), especially when combined with long work duration [1,9].

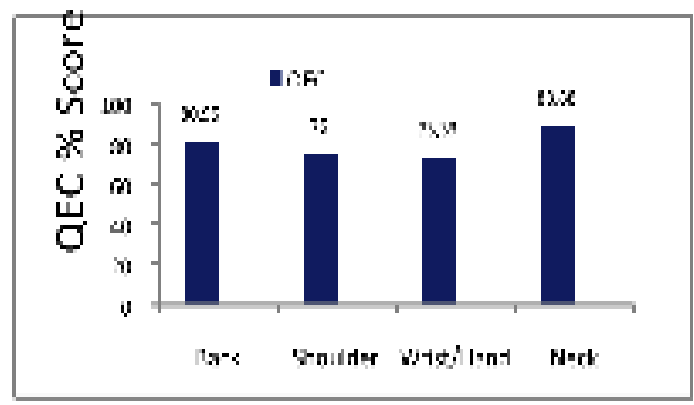

Figure 2. QEC scores of plucking operation

In plucking it was observed that the QEC score was the highest and was found 36 out of 42 . From the data it can be seen that there is a strong evidence to indicate that awkward wrist/hand posture is a risk factor for the development of wrist disorders among the tea leaf pluckers, especially in combination with other factors such as force, repetition and duration. Total exposure score for wrist/hand was found 34 out of maximum wrist/hand score 46 . The prevalence of wrist problems increases for tasks performed with the wrist deviated/flexed/extended from neutral.

\subsection{Design intervention}

Based on the relevant anthropometric measurements, an improved plucking basket was design to assist performance of plucking of tea leaf operation.
The designed basket was so designed that it fits the back of the workers so that it does not shift its position. Moreover the tapering shape of the improved basket allows the worker to move easily through the thick bushes. (Fig2).

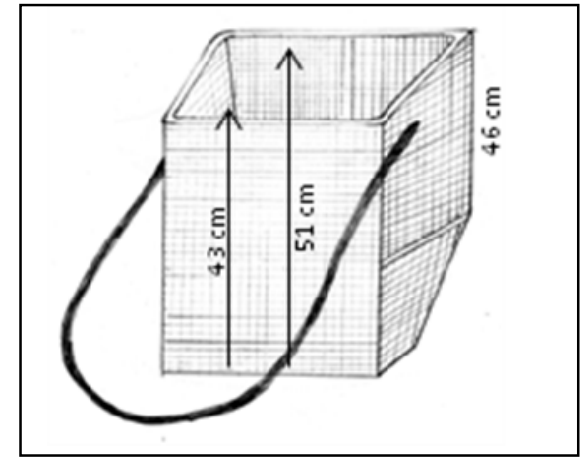

Figure 3. Measurements details of the improved basket

\subsection{Evaluation of designed basket}

Physiological stress comprised average and peak heart rate, energy expenditure, total cardiac cost of work and rating of perceived exertion, which is exhibited in Table 3.

Table 3

Physiological work load of women performing plucking

\begin{tabular}{|l|l|l|}
\hline \multirow{2}{*}{ Physiological parameters } & \multicolumn{2}{|l|}{ Types of tool } \\
\cline { 2 - 3 } & $\begin{array}{l}\text { Existing } \\
\text { basket }\end{array}$ & $\begin{array}{l}\text { Improved } \\
\text { basket }\end{array}$ \\
\hline $\begin{array}{l}\text { 1. Average working heart rate } \\
\text { (bpm) }\end{array}$ & 99.37 & 96.26 \\
2. Average peak heart rate (bpm) & 106.9 & 100.6 \\
3. Average energy expenditure & 7.07 & 6.57 \\
(kj/min) & & \\
4. Peak energy expenditure (kj/min) & 8.27 & 7.27 \\
5. Average TCCW (beats & 903.5 & 869.6 \\
6. Average PCW (beats/ min) & 22.58 & 21.74 \\
7. Average RPE (mean score) & 3.0 & 2.0 \\
8. Ease of comfort & 1.7 & 3.0 \\
\hline
\end{tabular}

Average working heart rate and Average peak heart rate of workers while performing plucking by using improved cane basket was 96.26 beats/min and 100.6 beats/min respectively. But while using existing bamboo basket both were found to be increased i.e. 99.37 beats $/ \mathrm{min}$ and 106.9 beats/min. (Table 3). Average TCCW with improved cane basket was 869.6 beats, which increased to 903.5 beats with existing basket.

Similarly physiological cost of work (PCW) was also increased to 22.58-beats/ $\mathrm{min}$ with existing basket in comparison to improved cane basket, which resulted 21.74-beats/ min. Worker considered plucking activity as light activity with improved basket in comparison to existing basket, with which the plucking activity was 
considered as moderately heavy activity. Plucking activity with improved cane basket was very comfortable as compared to the activity with existing basket, which was considered uncomfortable

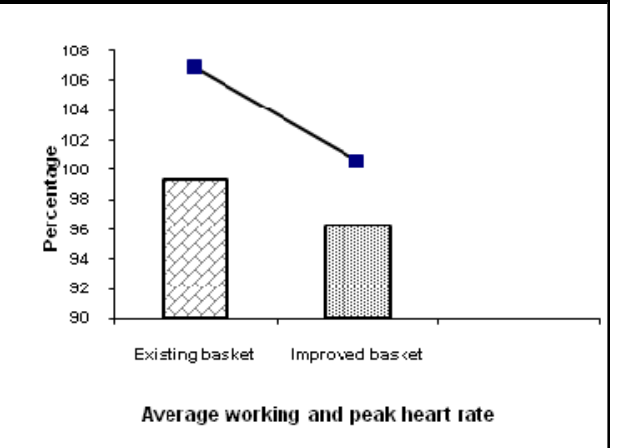

Figure 4. Average and peak heart rate while using existing and improved basket

\subsection{Musculoskeletal problems}

Table-4 illustrates that workers reported maximum pain in head and upper back (2.8), which was followed by neck (2.5), buttocks, lower back (2.0) etc. While using improved basket, there was reduction in musculoskeletal problem relating to head (1.3), neck (1.4) and upper back (1.6).

Table 4

Incidence of musculoskeletal problems using existing and improved tools

\begin{tabular}{|l|c|l|}
\hline Body parts & $\begin{array}{l}\text { Existing bamboo } \\
\text { basket }\end{array}$ & Improved basket \\
\hline Head & 2.8 & 1.3 \\
Neck & 2.5 & 1.4 \\
Shoulder & 1.0 & 1.0 \\
Upper beak & 2.8 & 1.6 \\
Upper arms & 1.0 & 1.0 \\
Elbow & - & - \\
Mid back & 1.0 & 0.9 \\
Lower arms & 1.6 & 1.0 \\
Lower back & 2.0 & 1.6 \\
Buttocks & 2.4 & - \\
Palms & 1.5 & 1.5 \\
Fingers & 2.2 & 2.2 \\
Legs & 1.2 & 1.2 \\
\hline
\end{tabular}

\section{Conclusion}

Both male and female workers were the main working force. They were actively involved in various activities with different workloads from light, moderately heavy to very heavy. While performing the activities they are forced to use age old technologies, which cause health related problems among the workers. The feelings of tiredness while performing activities and musculoskeletal problems faced by the workers lead to low productivity.

In order to reduce the incidence of health related problems among the workers and to increase the productivity, there is a need to change the working conditions i.e. the work, work method and the technologies they use to perform the various activities. An improved technology, skill labour and efficient managements are the factors of improving productivity. Moreover it is desirable that the activities should be carried out with breaks to give relief to the workers from undesirable physiological strain and fatigue. Importance should be given to ergonomic aspect of work, worker and work place in tea industry.

\section{References}

1. J.B. Carter and E.W. Banister, Musculoskeletal problems in VDT work: a review, Ergonomics, 1994, 37: 1623-1648.

2. D. Chakrabarti, Developing safe design and some occupational ergonomics issues, Proceedings Indian Science Congress, Section XI, Medical Sciences (Including Physiology) January, 2009, 6-7

3. G.M. Haslegrave, and E. N. Corlett, Factors affecting posture for machine sewing tasks : The need for changes in sewing machine design, Applied Ergonomics, 2005, (26), 35-46

4. National Institute for Occupational Safety and Health (NIOSH), (1997): Musculoskeletal Disorders and Workplace Factors: a Critical Review of Epidemiologic Evidence for Work-related Musculoskeletal Disorders of the Neck, Upper Extremity, and Low Back NIOSH Publication No. 97-141, 1995.

5. Occupational Safety and Health Administration, Occupational Safety and Health Administration (OSHA), USA, 2000, Ergonomics program standard. Federal Register /Rules and Regulations; 2000, 65:220,4. Washington, DC.

6. P.Parimalam, N.Kamalamma and A.K.Ganguli, Musculoskeletal problems of small scale industrial workers in Madurai - A situational analysis, Proceedings of Hwwe 2005., 904-911.

7. M.A.Varghese, P.N. Saha, and N.Atreya, A rapid appraisal of occupational workload from a modified scale of perceived exertion. Ergonomics, 37(3), 1994, 485-491.

8. R.H Westgaard, and A.Aarås, Postural muscle strain as a causal factor for development of work-related musculoskeletal illness, Appl. Ergon. 15, 1984, 162-174.

9. R.H. Westgaard, Work-related musculoskeletal complaints: some ergonomic challenges upon the start of the new century, Applied Ergonomics, 31, 2000, 569-580.

10. S.F. Wiker, D.B. Chaffin, and G.D. Langolf, Shoulder postural fatigue and discomfort. International Journal of Industrial Ergonomics 5 (2), 1990, 133-146. 